\title{
Coupled coincidence points for two mappings in metric spaces and cone metric spaces
}

\author{
Wei Long ${ }^{1 *}$, Billy E Rhoades ${ }^{2}$ and Miloje Rajovic ${ }^{3}$
}

\author{
* Correspondence: hopelw@126. \\ com \\ ${ }^{1}$ College of Mathematics and \\ Information Science, Jiangxi \\ Normal University, Nanchang, \\ Jiangxi 330022, People's Republic \\ of China \\ Full list of author information is \\ available at the end of the article
}

\begin{abstract}
This article is concerned with coupled coincidence points and common fixed points for two mappings in metric spaces and cone metric spaces. We first establish a coupled coincidence point theorem for two mappings and a common fixed point theorem for two $w$-compatible mappings in metric spaces. Then, by using a scalarization method, we extend our main theorems to cone metric spaces. Our results generalize and complement several earlier results in the literature. Especially, our main results complement a very recent result due to Abbas et al.
\end{abstract}

\section{Introduction}

Throughout this article, unless otherwise specified, we always suppose that $\mathbb{N}$ is the set of positive integers and $X$ is a nonempty set. In addition, for convenience, we denote $g x=g(x)$ for each $x \in X$ and each mapping $g: X \rightarrow X$.

Recently, Abbas et al. [1] introduced the following concept of $w$-compatible mappings:

Definition 1.1. The mappings $g: X \rightarrow X$ and $F: X \times X \rightarrow X$ are called $w$-compatible if $g(F(x, y))=F(g x, g y)$ whenever $g x=F(x, y)$ and $g y=F(y, x)$.

Moreover, they established several coupled coincidence point theorems and common fixed point theorems for such mappings. The problem investigated in [1] is interesting. In fact, recently, the existence of coupled fixed points, coupled coincidence points, coupled common fixed points, and common fixed points for nonlinear mappings with two variables has attracted more and more attention. For example, Bhashkar and Lakshmikantham [2] investigated some coupled fixed point theorems in partially ordered sets, and they also discussed an application of their result by investigating the existence and uniqueness of the solution for a periodic boundary value problem; Sabetghadam et al. [3] extended some results in [2] to cone metric spaces; Lakshmikantham and Ćirić [4] proved several coupled coincidence and coupled common fixed point theorems for nonlinear contractive mappings in partially ordered complete metric spaces; Karapinar [5] extended some results of [4] to cone metric spaces; Zoran and Mitrović [6] considered this topic in normed spaces and established a coupled best approximation theorem; Ding et al. [7] established some coupled coincidence and coupled common fixed point theorems in partially ordered metric spaces under some generalized contraction conditions; etc. 
The aim of this article is to make further studies on such problems, and to generalize and complement some known results. Next, let us recall some related definitions:

Definition 1.2. [1] Let $g: X \rightarrow X, F: X \times X \rightarrow X$ be two mappings.

(I) $(x, y) \in X \times X$ is called a coupled coincidence point of $F$ and $g$ if $g x=F(x, y)$ and $g y=F(y, x)$.

(II) $(x, y) \in X \times X$ is called a coupled fixed point of $F$ if $x=F(x, y)$ and $y=F(y, x)$.

(III) $x \in X$ is called a common fixed point of $F$ and $g$ if $x=g x=F(x, x)$.

\section{Metric spaces}

Now, let us present one of our main results.

Theorem 2.1. Let $(X, d)$ be a complete metric space. Assume that $g: X \rightarrow X$ and $F$ : $X \times X \rightarrow X$ are two mappings satisfying

(H1) there exists a non-decreasing function $\varphi:[0,+\infty) \rightarrow[0,+\infty)$ such that $\lim _{n \rightarrow \infty} \phi^{n}(t)=0$ for each $t>0$, and

$$
d(F(x, y), F(u, v)) \leq \phi\left[M_{F}^{g}(x, y, u, v)\right]
$$

for all $x, y, u, v \in X$, where

$$
\begin{array}{r}
M_{F}^{g}(x, y, u, v)=\max \{d(g x, g u), d(g y, g v), d(g x, F(x, y)), d(g u, F(u, v)), d(g y, F(y, x)), \\
\left.d(g v, F(v, u)), \frac{d(g x, F(u, v))+d(g u, F(x, y))}{2}, \frac{d(g y, F(v, u))+d(g v, F(y, x))}{2}\right\} ;
\end{array}
$$

(H2) $F(X \times X) \subseteq g(X)$, and $g(X)$ is a closed subset of $X$.

Then $F$ and $g$ have a coupled coincidence point in $X$.

Proof. First, let us present some properties about $\varphi$ which will be used in the sequel. We claim that $\varphi(t)<t$ for each $t>0$. In fact, if $\varphi\left(t_{0}\right) \geq t_{0}$ for some $t_{0}>0$, then, since $\varphi$ is non-decreasing, $\varphi^{n}\left(t_{0}\right) \geq t_{0}$ for all $n \in \mathbb{N}$, which contradicts the condition $\lim _{n \rightarrow \infty} \phi^{n}\left(t_{0}\right)=0$.

Moreover, it is easy to see that $\varphi(0)=0$, and thus $\varphi(t) \leq t$ for all $t \geq 0$.

Take $x_{0}, y_{0} \in X$. Since $F(X \times X) \subseteq g(X)$, one can construct two sequences $\left\{x_{n}\right\}$, $\left\{y_{n}\right\}$ in $X$ such that

$$
g x_{n}=F\left(x_{n-1}, y_{n-1}\right), g y_{n}=F\left(y_{n-1}, x_{n-1}\right), \quad n=1,2, \ldots
$$

For any fixed $n \in \mathbb{N}$, by (H1), we have

$$
d\left(g x_{n+1}, g x_{n}\right)=d\left(F\left(x_{n}, y_{n}\right), F\left(x_{n-1}, y_{n-1}\right)\right) \leq \phi\left(M_{n}\right),
$$

and

$$
d\left(g y_{n+1}, g y_{n}\right)=d\left(F\left(y_{n}, x_{n}\right), F\left(y_{n-1}, x_{n-1}\right)\right) \leq \phi\left(M_{n}\right),
$$

where

$$
\begin{aligned}
M_{n}= & \max \left\{d\left(g x_{n}, g x_{n-1}\right), d\left(g y_{n}, g y_{n-1}\right), d\left(g x_{n}, g x_{n+1}\right), d\left(g y_{n}, g y_{n+1}\right),\right. \\
& \left.\frac{d\left(g x_{n-1}, g x_{n+1}\right)}{2}, \frac{d\left(g y_{n-1}, g y_{n+1}\right)}{2}\right\} .
\end{aligned}
$$


Since

$$
\frac{d\left(g x_{n-1}, g x_{n+1}\right)}{2} \leq \frac{d\left(g x_{n-1}, g x_{n}\right)+d\left(g x_{n}, g x_{n+1}\right)}{2} \leq \max \left\{d\left(g x_{n-1}, g x_{n}\right), d\left(g x_{n}, g x_{n+1}\right)\right\}
$$

and

$$
\frac{d\left(g y_{n-1}, g y_{n+1}\right)}{2} \leq \frac{d\left(g y_{n-1}, g y_{n}\right)+d\left(g y_{n}, g y_{n+1}\right)}{2} \leq \max \left\{d\left(g y_{n-1}, g y_{n}\right), d\left(g y_{n}, g y_{n+1}\right)\right\},
$$

we have

$$
M_{n}=\max \left\{d\left(g x_{n}, g x_{n-1}\right), d\left(g y_{n}, g y_{n-1}\right), d\left(g x_{n}, g x_{n+1}\right), d\left(g y_{n}, g y_{n+1}\right)\right\} .
$$

Now, let us prove that for each $n \in \mathbb{N}$,

$$
M_{n}=\max \left\{d\left(g x_{n}, g x_{n-1}\right), d\left(g y_{n}, g y_{n-1}\right)\right\} .
$$

We consider the following three cases:

Case I. If $M_{n}=0$ or $M_{n}=\max \left\{d\left(g x_{n}, g x_{n-1}\right), d\left(g y_{n}, g y_{n-1}\right)\right\}$, then (2.3) obviously holds.

Case II. $M_{n}=d\left(g x_{n}, g x_{n+1}\right)>0$.

Then, by (2.1),

$$
d\left(g x_{n+1}, g x_{n}\right) \leq \phi\left(d\left(g x_{n}, g x_{n+1}\right)\right)<d\left(g x_{n}, g x_{n+1}\right),
$$

which is a contradiction.

Case III. $M_{n}=d\left(g y_{n}, g y_{n+1}\right)>0$.

Similar to Case II, by (2.2), we get a contradiction.

Thus, in all cases, (2.3) holds for each $n \in \mathbb{N}$. In addition, combining (2.1) and (2.2), we get that for all $n \in \mathbb{N}$ :

$$
M_{n+1}=\max \left\{d\left(g x_{n+1}, g x_{n}\right), d\left(g y_{n+1}, g y_{n}\right)\right\} \leq \phi\left(M_{n}\right) \cdots \leq \phi^{n}\left(M_{1}\right) .
$$

Let $\varepsilon>0$ be fixed. Since $\lim _{n \rightarrow \infty} \phi^{n}\left(M_{1}\right)=0$, by (2.5), there exists $N \in \mathbb{N}$ such that for all $n>N$,

$$
M_{n+1}<\varepsilon-\phi(\varepsilon) .
$$

Throughout the rest of this article, we denote

$$
M_{n}^{p}=\max \left\{d\left(g x_{n+p}, g x_{n}\right), d\left(g y_{n}, g y_{n+p}\right)\right\}
$$

for each $p \in \mathbb{N}$ and each $n \in \mathbb{N}$.

Let $n>N$ be fixed. Let us show that for all $p \in \mathbb{N}$ :

$$
M_{n}^{p} \leq \varepsilon
$$

By (2.6), we have

$$
M_{n}^{1}=M_{n+1}<\varepsilon-\phi(\varepsilon)<\varepsilon .
$$


By (2.5) and (2.6), we get

$$
\begin{aligned}
M_{n}^{2} & =\max \left\{d\left(g x_{n+2}, g x_{n}\right), d\left(g y_{n+2}, g y_{n}\right)\right\} \\
& \leq \max \left\{d\left(g x_{n+2}, g x_{n+1}\right), d\left(g y_{n+2}, g y_{n+1}\right)\right\}+\max \left\{d\left(g x_{n+1}, g x_{n}\right), d\left(g y_{n+1}, g y_{n}\right)\right\} \\
& =M_{n+2}+M_{n+1} \\
& \leq \phi\left(M_{n+1}\right)+M_{n+1} \\
& \leq \phi(\varepsilon)+\varepsilon-\phi(\varepsilon)=\varepsilon .
\end{aligned}
$$

Next, let us show that $M_{n}^{3} \leq \varepsilon$. By $(\mathrm{H} 1)$, we have

$$
\begin{aligned}
M_{n+1}^{2} & =\max \left\{d\left(g x_{n+3}, g x_{n+1}\right), d\left(g y_{n+3}, g y_{n+1}\right)\right\} \\
& =\max \left\{d\left(F\left(x_{n+2}, y_{n+2}\right), F\left(x_{n}, y_{n}\right)\right), d\left(F\left(y_{n+2}, x_{n+2}\right), F\left(y_{n}, x_{n}\right)\right)\right\} \\
& \leq \phi\left(a_{n}\right)
\end{aligned}
$$

where

$$
\begin{aligned}
a_{n}= & \max \left\{d\left(g x_{n+2}, g x_{n}\right), d\left(g y_{n}, g y_{n+2}\right), d\left(g x_{n+2}, g x_{n+3}\right), d\left(g y_{n+2}, g y_{n+3}\right), d\left(g x_{n}, g x_{n+1}\right),\right. \\
& \left.d\left(g y_{n}, g y_{n+1}\right), \frac{d\left(g x_{n+2}, g x_{n+1}\right)+d\left(g x_{n}, g x_{n+3}\right)}{2}, \frac{d\left(g y_{n+2}, g y_{n+1}\right)+d\left(g y_{n}, g y_{n+3}\right)}{2}\right\} \\
= & \max \left\{M_{n}^{2}, M_{n+3}, M_{n+1}, \frac{d\left(g x_{n+2}, g x_{n+1}\right)+d\left(g x_{n}, g x_{n+3}\right)}{2}, \frac{d\left(g y_{n+2}, g y_{n+1}\right)+d\left(g y_{n}, g y_{n+3}\right)}{2}\right\} \\
\leq & \max \left\{\varepsilon, \frac{d\left(g x_{n+2}, g x_{n+1}\right)+d\left(g x_{n}, g x_{n+3}\right)}{2}, \frac{d\left(g y_{n+2}, g y_{n+1}\right)+d\left(g y_{n}, g y_{n+3}\right)}{2}\right\} .
\end{aligned}
$$

If

$$
a_{n}=\frac{d\left(g x_{n+2}, g x_{n+1}\right)+d\left(g x_{n}, g x_{n+3}\right)}{2}
$$

then by (2.5) and (2.8),

$$
\begin{aligned}
d\left(g x_{n+3}, g x_{n+1}\right) & \leq \phi\left(a_{n}\right) \leq a_{n}=\frac{d\left(g x_{n+2}, g x_{n+1}\right)+d\left(g x_{n}, g x_{n+3}\right)}{2} \\
& \leq \frac{M_{n+2}+d\left(g x_{n}, g x_{n+3}\right)}{2} \leq \frac{\phi(\varepsilon)+d\left(g x_{n}, g x_{n+3}\right)}{2}
\end{aligned}
$$

which yields

$$
\begin{aligned}
& d\left(g x_{n}, g x_{n+3}\right) \leq d\left(g x_{n+3}, g x_{n+1}\right)+\left(g x_{n+1}, g x_{n}\right) \\
& \leq \frac{\phi(\varepsilon)+d\left(g x_{n}, g x_{n+3}\right)}{2}+\varepsilon-\phi(\varepsilon) \\
&=\varepsilon-\frac{\phi(\varepsilon)}{2}+\frac{d\left(g x_{n}, g x_{n+3}\right)}{2}, \\
& \text { i.e., } \frac{d\left(g x_{n}, g x_{n+3}\right)}{2} \leq \varepsilon-\frac{\phi(\varepsilon)}{2} \text {. Thus, } \\
& a_{n}=\frac{d\left(g x_{n+2}, g x_{n+1}\right)+d\left(g x_{n}, g x_{n+3}\right)}{2} \leq \frac{M_{n+2}+d\left(g x_{n}, g x_{n+3}\right)}{2} \leq \frac{\phi(\varepsilon)}{2}+\frac{d\left(g x_{n}, g x_{n+3}\right)}{2} \leq \varepsilon .
\end{aligned}
$$

If $a_{n}=\frac{d\left(g y_{n+2}, g y_{n+1}\right)+d\left(g y_{n}, g y_{n+3}\right)}{2}$, one can similarly show that $a_{n} \leq \varepsilon$. Hence, in all cases, $a_{n} \leq \varepsilon$, so that $M_{n+1}^{2} \leq \phi(\varepsilon)$. Then, by (2.6), we get 


$$
\begin{aligned}
M_{n}^{3} & =\max \left\{d\left(g x_{n+3}, g x_{n}\right), d\left(g y_{n+3}, g y_{n}\right)\right\} \\
& \leq \max \left\{d\left(g x_{n+3}, g x_{n+1}\right), d\left(g y_{n+3}, g y_{n+1}\right)\right\}+\max \left\{d\left(g x_{n+1}, g x_{n}\right), d\left(g y_{n+1}, g y_{n}\right)\right\} \\
& =M_{n+1}^{2}+M_{n+1} \\
& \leq \phi(\varepsilon)+\varepsilon-\phi(\varepsilon)=\varepsilon .
\end{aligned}
$$

In general, in order to prove that $M_{n}^{p} \leq \varepsilon$, one can first show that $M_{n+1}^{p-1} \leq \phi(\varepsilon)$, and then by the inequality $M_{n}^{p} \leq M_{n+1}^{p-1}+M_{n+1}$, the conclusion follows easily.

Now, we have proved that (2.7) holds for all $p \in \mathbb{N}$, which means that $\left\{g x_{n}\right\}$ and $\left\{g y_{n}\right\}$ are Cauchy sequences. Then, by the completeness of $g(X)$, there exist $x, y \in X$ such that

$$
\lim _{n \rightarrow \infty} g x_{n}=g x, \quad \lim _{n \rightarrow \infty} g y_{n}=g y .
$$

By (H1) we have

$$
d(F(x, y), g x) \leq d\left(F(x, y), F\left(x_{n}, y_{n}\right)\right)+d\left(g x_{n+1}, g x\right) \leq \phi\left(c_{n}\right)+d\left(g x_{n+1}, g x\right),
$$

and

$$
d(F(y, x), g y) \leq d\left(F(y, x), F\left(y_{n}, x_{n}\right)\right)+d\left(g y_{n+1}, g y\right) \leq \phi\left(c_{n}\right)+d\left(g y_{n+1}, g y\right),
$$

where

$$
\begin{aligned}
c_{n}= & \max \left\{d\left(g x, g x_{n}\right), d\left(g y, g y_{n}\right), d(g x, F(x, y)), d(g y, F(y, x)), d\left(g x_{n}, g x_{n+1}\right),\right. \\
& \left.d\left(g y_{n}, g y_{n+1}\right), \frac{d\left(g x, g x_{n+1}\right)+d\left(g x_{n}, F(x, y)\right)}{2}, \frac{d\left(g y, g y_{n+1}\right)+d\left(g y_{n}, F(y, x)\right)}{2}\right\} .
\end{aligned}
$$

Now, we claim that $g x=F(x, y)$ and $g y=F(y, x)$. In fact, if this is not true, then

$$
\max \{d(g x, F(x, y)), d(g y, F(y, x))\}>0,
$$

which, together with (2.9), yield that $c_{n}=\max \{d(g x, F(x, y)), d(g y, F(y, x))\}$ when $n$ is sufficiently large. Letting $n \rightarrow \infty$ in (2.10) and (2.11), it follows that

$$
d(F(x, y), g x) \leq \phi\left(c_{n}\right)<\max \{d(g x, F(x, y)), d(g y, F(y, x))\}
$$

and

$$
d(F(y, x), g y) \leq \phi\left(c_{n}\right)<\max \{d(g x, F(x, y)), d(g y, F(y, x))\} .
$$

This is a contradiction. Thus, $g x=F(x, y)$ and $g y=F(y, x)$, i.e., $(x, y)$ is a coupled coincidence point of $F$ and $g$.

Example 2.2. Let $X=[2,+\infty), d(x, y)=|x-y|, F(x, y)=x+y, g(x)=x^{2}$, and $\phi(t)=\frac{t}{2}$.

It is easy to verify that all the assumptions of Theorem 2.1 are satisfied. So $F$ and $g$ have a coupled coincidence point. In fact, we have $F(2,2)=g(2)$.

If $F$ and $g$ are $w$-compatible, we have the following result:

Theorem 2.3. Suppose that all of the assumptions of Theorem 2.1 are satisfied, and $F$ and $g$ are w-compatible. Then $F$ and $g$ have a unique common fixed point.

Proof. We give the proof in 3 steps. 
Step 1. We claim that if

$$
g x_{1}=F\left(x_{1}, y_{1}\right), \quad g y_{1}=F\left(y_{1}, x_{1}\right), \quad g x_{2}=F\left(x_{2}, y_{2}\right), \quad g y_{2}=F\left(y_{2}, x_{2}\right),
$$

then $g x_{1}=g x_{2}=g y_{1}=g y_{2}$. In fact, by (H1), we have

$$
d\left(g x_{1}, g x_{2}\right)=d\left(F\left(x_{1}, y_{1}\right), F\left(x_{2}, y_{2}\right)\right) \leq \phi(\omega)
$$

and

$$
d\left(g y_{1}, g y_{2}\right)=d\left(F\left(y_{1}, x_{1}\right), F\left(y_{2}, x_{2}\right)\right) \leq \phi(\omega),
$$

where $\omega=M_{F}^{g}\left(x_{1}, y_{1}, x_{2}, y_{2}\right)=M_{F}^{g}\left(y_{1}, x_{1}, y_{2}, x_{2}\right)=\max \left\{d\left(g x_{1}, g x_{2}\right), d\left(g y_{1}, g y_{2}\right)\right\}$. Then, it follows that

$$
\omega=\max \left\{d\left(g x_{1}, g x_{2}\right), d\left(g y_{1}, g y_{2}\right)\right\} \leq \phi(\omega),
$$

which gives that $\omega=0$, i.e., $g x_{1}=g x_{2}$ and $g y_{1}=g y_{2}$.

By a similar argument, in the case of

$$
g x_{1}=F\left(x_{1}, y_{1}\right), g y_{1}=F\left(y_{1}, x_{1}\right), \quad g x_{2}=F\left(x_{2}, y_{2}\right), \quad g y_{2}=F\left(y_{2}, x_{2}\right),
$$

one can also show that $g x_{1}=g y_{2}$ and $g y_{1}=g x_{2}$. Then, it follows that

$$
g x_{1}=g y_{1}=g x_{2}=g y_{2} \text {. }
$$

Step 2. By Theorem 2.1, $(x, y)$ is a coupled coincidence point of $F$ and $g$, i.e., $g x=F$ $(x, y)$ and $g y=F(y, x)$. Then, by Step 1 , we have $g x=g y$. Let $u=g x=g y$. Since $F$ and $g$ are $w$-compatible, we have

$$
g u=g(g x)=g(F(x, y))=F(g x, g y)=F(u, u) .
$$

Again by Step 1, one obtains $g u=g x$. Thus $u=g x=g u=F(u, u)$, i.e., $u$ is a common fixed point of $F$ and $g$.

Step 3. Let $v=g v=F(v, v)$. By Step 1, one can deduce that $g v=g u$. So $u=g u=g v$ $=v$, which means that $u$ is the unique common fixed point of $F$ and $g$.

\section{Applications to cone metric spaces}

In this section, by a scalarization method used in [7], we apply our main results in metric spaces to cone metric spaces, and obtain some new theorems.

In the following, we always suppose that $E$ is a Banach space, $P$ is a convex cone in $E$ with int $P \neq 0, \preccurlyeq$ is the partial ordering induced by $P,(X, \rho)$ is a cone metric space with the underlying cone $P, e \in \operatorname{int} P$, and $\xi_{e}: E \rightarrow \mathbb{R}$ is defined by

$$
\xi_{e}(y)=\inf \{r \in \mathbb{R}: y \in \text { re }-P\}, \quad y \in E .
$$

In addition, $x \gg y$ stands for $x-y \in \operatorname{int} P$.

First, let us recall some definitions about cone metric space.

Definition 3.1. [8] Let $X$ be a nonempty set and $P$ be a cone in a Banach space E. Suppose that a mapping $d: X \times X \rightarrow E$ satisfies: 
(d1) $\theta \leqslant \rho(x, y)$ for all $x, y \in X$ and $\rho(x, y)=\theta$ if and only if $x=y$, where $\theta$ is the zero element of $P$;

(d2) $\rho(x, y)=\rho(y, x)$ for all $x, y \in X$;

(d3) $\rho(x, y) \leqslant \rho(x, z)+\rho(z, y)$ for all $x, y, z \in X$.

Then $\rho$ is called a cone metric on $X$ and $(X, \rho)$ is called a cone metric space.

Definition 3.2. Let $(X, \rho)$ be a cone metric space. Let $\left\{x_{n}\right\}$ be a sequence in $X$ and $x \in$ $X$. If $\forall c \gg \theta$, there exists $N \in \mathbb{N}$ such that for all $n>N, \rho\left(x_{n}, x\right) \ll c$, then we say that $\left\{x_{n}\right\}$ converges to $x$, and we denote it by $\lim _{n \rightarrow \infty} x_{n}=x_{\text {or }} x_{n} \rightarrow x, n \rightarrow \infty$. If $\forall c \gg \theta$, there exists $N \in \mathbb{N}$ such that for all $n, m>N, \rho\left(x_{n}, x_{m}\right) \ll c$, then $\left\{x_{n}\right\}$ is called a Cauchy sequence in $X$. In addition, $(X, \rho)$ is called complete cone metric space if every Cauchy sequence is convergent.

Recall that it has been of great interest for many authors to study fixed point theorems in cone metric spaces, and there is a large literature on this topic. We refer the reader to $[1,3,5,7,9-28]$ and the references therein for some recent developments on this topic.

Next, let us recall some notations and basic results about the scalarization function $\xi_{e}$.

Lemma 3.3. [[7], Lemma 1.1] The following statements are true:

(i) $\xi_{e}(\cdot)$ is positively homogeneous and continuous on $E$;

(ii) $y, z \in E$ with $y \leqslant z$ implies $\xi_{e}(y) \leq \xi_{e}(z)$;

(ii) $\xi_{e}(y+z) \leq \xi_{e}(y)+\xi_{e}(z)$ for all $y, z \in E$.

Combining Theorems 2.1 and 2.2 of [7] and, we have the following results:

Theorem 3.4. Let $(X, \rho)$ be a cone metric space with underlying cone $P$. Then, $\xi_{e} \circ \rho$ is a metric on $X$. Moreover, if $(X, \rho)$ is complete, then $\left(X, \xi_{e} \circ \rho\right)$ is a complete metric space.

By using Theorems 2.1 and 2.3, one can deduce many results on cone metric spaces. For example, we have the following theorem:

Theorem 3.5. Let $(X, \rho)$ be a cone metric space with underlying cone P. Assume that $g: X \rightarrow X$ and $F: X \times X \rightarrow X$ are two mappings satisfying that $F(X \times X) \subseteq g(X), g(X)$ is a complete cone metric space, and there exists a constant $\lambda \in(0,1)$ such that for each $x$, $y, u, v \in X$, there is a $z \in S_{F}^{g}(x, y, u, v)$ with

$$
\rho(F(x, y), F(u, v)) \preccurlyeq \lambda z,
$$

where

$$
\begin{array}{r}
S_{F}^{g}(x, y, u, v)=\operatorname{co}\{\rho(g x, g u), \rho(g y, g v), \rho(g x, F(x, y)), \rho(g u, F(u, v)), \rho(g \gamma, F(y, x)), \\
\left.\rho(g v, F(v, u)), \frac{\rho(g x, F(u, v))+\rho(g u, F(x, y))}{2}, \frac{\rho(g y, F(v, u))+\rho(g v, F(y, x))}{2}\right\},
\end{array}
$$

and co denotes the convex hull. Then $F$ and $g$ have a coupled coincidence point in $X$. Moreover, if $F$ and $g$ are w-compatible, then $F$ and $g$ have a unique common fixed point.

Proof. Let $d=\xi_{e} \circ \rho$. By Theorem 3.4, $d$ is a metric on $X$ and $(g(X), d)$ is a complete metric space. Then, by Lemma 3.3, we have 


$$
d(F(x, y), F(u, v)) \leq \lambda \cdot \xi_{e}(z) \leq \lambda \cdot M_{F}^{g}(x, y, u, v),
$$

where $M_{F}^{g}(x, y, u, v)$ is defined in Theorem 2.1. Now, letting

$$
\phi(t)=\lambda t,
$$

it is easy to see that all of the assumptions of Theorem 2.1 are satisfied. Thus $F$ and $g$ have a coupled coincidence point in $X$. In addition, if $F$ and $g$ are $w$-compatible, by Theorem 2.3, $F$ and $g$ have a unique common fixed point.

Remark 3.6. Theorem 3.5 is a complement of [[1], Theorem 2.4]. Moreover, Theorem 3.5 extends some existing results. For example, one can deduce [[3], Theorem 2.2] from Theorem 3.5. In addition, note that Theorems 3.4 and 3.5 are true and in the context of tvs-cone metric spaces (for details see [23,28]).

Remark 3.7. It is needed to note that one can also get Theorem 3.5 by using the method of Minkowski functional, which is introduced in [22].

\section{Acknowledgements}

The authors thank the referees for their valuable comments that helped to improve the text. Wei Long acknowledges support from the NSF of China (11101192), the Key Project of Chinese Ministry of Education (211090), the NSF of Jiangxi Province of China (20114BAB211002), and the Foundation of Jiangxi Provincial Education Department (GJJ12205). Third author is thankful to the Ministry of Science and Technological Development of Serbia.

\section{Author details}

${ }^{1}$ College of Mathematics and Information Science, Jiangxi Normal University, Nanchang, Jiangxi 330022, People's Republic of China ${ }^{2}$ Department of Mathematics, Indiana University, Bloomington, IN 47405-7106, USA ${ }^{3}$ Faculty of Mechanical Engineering, University of Kragujevac, Dositejeva 19, 36000 Kraljevo, Serbia

\section{Authors' contributions}

All authors contributed equally and significantly in writing this paper. All authors read and approved the final manuscript.

\section{Competing interests}

The authors declare that they have no competing interests.

Received: 24 November 2011 Accepted: 23 April 2012 Published: 23 April 2012

\section{References}

1. Abbas, M, Ali Khan, M, Radenović, S: Common coupled fixed point theorems in cone metric spaces for w-compatible mappings. Appl Math Comput. 217, 195-202 (2010). doi:10.1016/j.amc.2010.05.042

2. Gnana Bhaskar, T, Lakshmikantham, V: Fixed point theorems in partially ordered metric spaces and applications. Nonlinear Anal. 65, 1379-1393 (2006). doi:10.1016/j.na.2005.10.017

3. Sabetghadam, F, Masiha, HP, Sanatpour, AH: Some coupled fixed point theorems in cone metric space. Fixed Point Theory Appl 2009, 8 (2009). (Article ID 125426)

4. Lakshmikantham, V, Ćirić, L: Coupled fixed point theorems for nonlinear contractions in partially ordered metric spaces. Nonlinear Anal. 70, 4341-4349 (2009). doi:10.1016/j.na.2008.09.020

5. Karapinar, E: Couple fixed point theorems for nonlinear contractions in cone metric spaces. Comput Math Appl. 59, 3656-3668 (2010). doi:10.1016/j.camwa.2010.03.062

6. Mitrović, ZD: A coupled best approximations theorem in normed spaces. Nonlinear Anal. 72, 4049-4052 (2010). doi:10.1016/j.na.2010.01.035

7. Ding, HS, Li, L, Radojević, S: Coupled coincidence point theorems for generalized nonlinear contraction in partially ordered metric spaces. Fixed Point Theory Appl. 2012, 96 (2012)

8. Du, WS: A note on cone metric fixed point theory and its equivalence. Nonlinear Anal. 72, 2259-2261 (2010). doi:10.1016/j.na.2009.10.026

9. Huang, LG, Zhang, X: Cone metric spaces and fixed point theorems of contractive mappings. J Math Anal Appl. 332, 1468-1476 (2007). doi:10.1016/j.jmaa.2005.03.087

10. Abbas, M, Jungck, G: Common fixed point results of noncommuting mappings without continuity in cone metric spaces. J Math Anal Appl. 341, 418-420 (2008)

11. Altun, I, Durmaz, G: Some fixed point results in cone metric spaces. Rendiconti del Circolo Mathematico di Palermo. 58, 319-325 (2009). doi:10.1007/s12215-009-0026-y

12. Altun, I, Damjanović, B, Djorić, D: Fixed point and common fixed point theorems on ordered cone metric spaces. Appl Math Lett. 23, 310-316 (2010). doi:10.1016/j.aml.2009.09.016

13. Ding, HS, Li, L: Coupled fixed point theorems in partially ordered cone metric spaces. Filomat. 25, 137-149 (2011) 
14. Ding, HS, Li, L, Long, W: Coupled common fixed point theorems for weakly increasing mappings with two variables. J Comput Anal Appl to appear

15. Dorić, D, Kadelburg, Z, Radenović, S: Coupled fixed point for mappings without mixed monotone property. Appl Math Lett (2012). doi: 10.1016/j.aml.2012.02.022

16. Golubović, Z, Kadelburg, Z, Radenović, S: Coupled coincidence points of mappings in ordered partial metric spaces. Abstr Appl Anal 2012, 18 (2012). (Article ID 192581)

17. Ilić, D, Rakočević, V: Common fixed points for maps on cone metric space. J Math Anal Appl. 341, 876-882 (2008). doi:10.1016/j.jmaa.2007.10.065

18. Ilić, D, Rakočević, V: Quasi-contraction on a cone metric space. Appl Math Lett. 22, 728-731 (2009). doi:10.1016/j. aml.2008.08.011

19. Janković, S, Kadelburg, Z, Radenović, S: Rhoades BE: Assad-Kirk-type fixed point theorems for a pair of nonself mappings on cone metric spaces. Fixed Point Theory Appl 2009, 16 (2009). (Article ID 761086)

20. Jungck, G, Radenović, S, Radojević, S, Rakočević, V: Common fixed point theorems for weakly compatible pairs on cone metric spaces. Fixed Point Theory Appl 2009, 13 (2009). (Article ID 643840)

21. Kadelburg, Z, Radenović, S, Rakočvić, V: Remarks on quasi-contraction on a cone metric space. Appl Math Lett. 22, 1674-1679 (2009). doi:10.1016/j.aml.2009.06.003

22. Kadelburg, Z, Pavlović, M, Radenović, S: Common fixed point theorems for ordered contractions and quasicontractions in ordered cone metric spaces. Comput Math Appl. 59, 3148-3159 (2010). doi:10.1016/j.camwa.2010.02.039

23. Kadelburg, Z, Radenović, $S$, Rakočević, V: A note on the equivalence of some metric and cone metric fixed point results. Appl Math Lett. 24, 370-374 (2011). doi:10.1016/j.aml.2010.10.030

24. Kadelburg, Z, Radenović, S: Coupled fixed point results under tvs-cone metric and w-cone-distance. Adv Fixed Point Theory. (2012, in press)

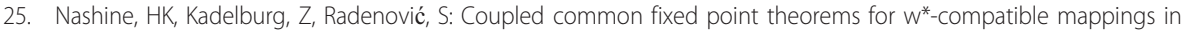
ordered cone metric spaces. Appl Math Comput. 218, 5422-5432 (2012). doi:10.1016/j.amc.2011.11.029

26. Radenović, S, Rhoades, BE: Fixed point theorem for two non-self mappings in cone metric spaces. Comput Math Appl. 57, 1701-1707 (2009). doi:10.1016/j.camwa.2009.03.058

27. Rezapour, Sh, Hamlbarani, R: Some note on the paper "Cone metric spaces and fixed point theorems of contractive mappings". J Math Anal Appl. 345, 719-724 (2008). doi:10.1016/j.jmaa.2008.04.049

28. Rezapour, Sh, Haghi, RH, Shahzad, N: Some notes on fixed points of quasi-contraction maps. Appl Math Lett. 23, 498-502 (2010). doi:10.1016/j.aml.2010.01.003

29. Zhang, X: Fixed point theorem of generalized quasicontractive mapping in cone metric spaces. Comput Math Appl (2011). doi:10.1016/j.camwa.2011.03.107

doi:10.1186/1687-1812-2012-66

Cite this article as: Long et al:: Coupled coincidence points for two mappings in metric spaces and cone metric spaces. Fixed Point Theory and Applications 2012 2012:66.

\section{Submit your manuscript to a SpringerOpen ${ }^{\circ}$ journal and benefit from:}

- Convenient online submission

- Rigorous peer review

- Immediate publication on acceptance

- Open access: articles freely available online

- High visibility within the field

- Retaining the copyright to your article

Submit your next manuscript at $\boldsymbol{\wedge}$ springeropen.com 